\title{
Development and Characterization of Fast Dissolving Buccal Strip of Frovatriptan Succinate Monoydrate for Buccal Delivery
}

\author{
Pankaj Bhatt*, Suruchi Singh, Satish Kumar Sharma, Sani Rabiu \\ School of Pharmacy, Glocal University, Mirzapur Pole, Uttar Pradesh, INDIA.
}

\begin{abstract}
Objectives: Aim of the present research work is to prepared fast mouth dissolving film of frovatriptan succinate monoydrate. Methods: Fast dissolving buccal film is prepared by Solvent casting method, hydroxypropyl methylcellulose E3 and E15 are helpful in the film-forming polymer, plasticizer in polyethylene glycols disintegrant is croscarmellose sodium, the artificial sweetener in Sodium saccharin as, citric acid as saliva stimulant, fructose as diluents and natural sweetener, wild cherry as a flavour and Brilliant blue dye for elegance was selected for fast dissolving film preparation. By prism, software result is obtained and then evaluated using analysis of variance (ANOVA). Results: The result suggested that the formulation containing $20 \% \mathrm{w} / \mathrm{w}$ Sodium saccharin, $10 \% \mathrm{w} / \mathrm{w}$ fructose and $5 \%$ citric acid was found to effectively obscure the bitter taste of drug with best overall acceptability. The same composition of Sodium saccharin, citric acid and fructose were used for further optimization using design of an experiment to continue obscuring the bitter taste of frovatriptan succinate monoydrate. Simple lattice mixture design which is helpful in drug
\end{abstract}

formulation by using polymer plasticizer and disintegrant concentration for disintegration time-independent variable tensile strength and percentage elongation for the response. Conclusion: The effect of each variable, two and three-factor interactions were studied. The batches were numerically optimized to give a design space. fast mouth dissolving films are also found to behave better patient compliance in all the age groups.

Key words: Migraine, Fast Dissolving Film, Solvent casting method, Stability studies, Frovatriptan succinate monoydrate.

\section{Correspondence}

Mr. Pankaj Bhatt

School of Pharmacy, Glocal University, Mirzapur Pole-247121, Uttar Pradesh, INDIA.

Phone no: +919045781973

Email: pankajbhattb.pharma@gmail.com

DOI: 10.5530/ijpi.2021.1.13

\section{INTRODUCTION}

Migraine: Migraine is more commonly found in women than in men. In percentage, it is $20.7 \%$ in female and $9 \%$ in male. It is an episodic neurovascular disorder that occurs by severe attacks; the symptoms of unilateral pulsatile headache are nausea, photophobia and phonophobia. ${ }^{1}$ As it is related to prolonged disability and seen in Healthcare place. They are very painful and make a person weak. ${ }^{2}$ It is the main issue responsible for absenteeism in the workplace or school. ${ }^{3}$ Headache that occurs due to tension is maximum among people, followed by a migraine headache, but it is excruciating out of all these migraines are found most common. ${ }^{4}$ The oral route is the most preferred route of administration for systemic effect. About $60 \%$ of all formulations are of the solid dosage form. Tablet is the most preferred dosage form due to ease of transportation, manufacturing and more patient compliance. After swallowing the conventional tablet, some patient faces some difficulties like a paediatric, geriatric and forbidden patient. To rectify this issue, a formulation was being developed, i.e. oral fast dissolving film. ${ }^{5}$ Oral dissolving films can be used anytime in the absence of water. Fast dissolving film shows faster dissolution due to least integration time. Sweeteners and flavours are added in preparation fast dissolving films which help in curing the patients. ${ }^{6,7}$

Frovatriptan succinate monohydrate is a 5-HT receptor agonist which binds with high affinity to $5-\mathrm{HT}_{1 \mathrm{~B}}$ and $5-\mathrm{HT}_{1 \mathrm{D}}$ receptors. ${ }^{8}$ In vitro, frovatriptan succinate monohydrate shows a moderate affinity for the receptor 5-HT7, which is believed to contribute to its distinctive pharmacologic properties. ${ }^{9}$ Frovatriptan succinate monoydrate demonstrated higher binding affinity than sumatriptan at the human $5-\mathrm{HT}_{1 \mathrm{~B}}$ receptor $(\sim 4$-fold $)$ and a comparable affinity at the human
5-HT ${ }_{1 \mathrm{D}}$ receptor. ${ }^{10}$ The absolute oral bioavailability of Frovatriptan succinate monohydrate is $22 \%-30 \%$. The mean time to reach peak plasma concentration $\left(\mathrm{T}_{\max }\right)$ is approximately 2-3 hr. Food does not influence the pharmacokinetics of frovatriptan succinate monoydrate. ${ }^{11}$

\section{MATERIALS AND METHODS}

\section{Materials}

Frovatriptan succinate monohydrate, Hydroxypropyl Methylcellulose, Hydroxypropyl cellulose, Polyethylene glycol 400, polyethylene glycols, Glycerol, Fructose, Maltodextrin, Mannitol, Sodium Starch Glycolate, Crospovidone, Croscarmellose Sodium, Citric Acid, Sodium saccharin were used of analytical grade.

\section{Methods}

The drug and excipients were individually weighed and dispensed. The polymer was slowly dissolved in water under constant stirring at $600 \mathrm{rpm}$, followed by the addition of plasticizer, sweetener, citric acid, disintegrant, drug, colour and flavour. The solution was stirred for $2 \mathrm{hr}$ to ensure a perfectly homogeneous mixture is obtained. The foam formed after stirring was removed by sonicating and degassing the solution, to obtain the final solution for fast dissolving buccal casting. The calculated amount of the solution was poured on Petri plates and specially fabricated rectangular glass plate. The Petri plates and rectangular glass plate was kept in an oven at $60^{\circ} \mathrm{C}$ for $4 \mathrm{hr}$ for drying the solution. Fast dissolving buccal film formed after drying were carefully removed and cut into the desired size. The fast dissolving buccal film were packed in Aluminium 
wraps and sealed with the help of tagger sealer and stored until further evaluation was carried out.

\section{Polymer selection, diluent and disintegrant}

On drug-polymer compatibility, diluent and disintegrant studies Hydroxypropyl methylcellulose (HPMC), Hydroxypropyl cellulose (HPC), Polyvinylpyrrolidone (PVP) of different grades and ratios were used for the primary selection between the polymers diluent and disintegrant.

\section{Characterization of the fast dissolving buccal film}

Physical appearance/surface texture: After visual inspection of the fast dissolving buccal Film evaluation was done according to the surface texture or by feel or touch.

Thickness uniformity: By using digital Vernier calliper thickness was measured.

Uniformity of dosage units: The films were tested for uniformity of dosage form by the UV-Spectrophotometric method. Three different fast dissolving film of the same formulation was dissolved in $100 \mathrm{ml}$ of Phosphate buffer $\mathrm{pH} 6.8$ medium; $2 \mathrm{ml}$ of this solution was diluted up to $10 \mathrm{ml}$ with Phosphate buffer $\mathrm{pH} 6.8$ medium to give a $7.8 \mathrm{ppm}$ solution. The absorbance of the solution was measured at $244 \mathrm{~nm}$ using a UV visible spectrophotometer. The standard solution of the raw drug of the same concentration was used as a bracketing standard after every six samples. By finding a standard graph percentage of drug content was being calculated and the same steps are repeated to other fast dissolving buccal film and the average drug content and standard deviation of each formulation was determined. This procedure was repeated for all 14 DOE formulations.

\section{Assay}

Formulation of 20 films were taken to dissolve it in $100 \mathrm{ml}$ volumetric flask with purified water as medium (Stock I). From the Stock I solution equivalent to a single dose was calculated and was diluted with $100 \mathrm{ml}$ of purified water. $2 \mathrm{ml}$ of the solution is diluted till $10 \mathrm{ml}$ with distilled water and its absorbance was measured at $244 \mathrm{~nm}$ using a UV visible spectrophotometer. The standard solution of the raw drug of the same concentration was used as a bracketing standard after every ten samples. The $\%$ drug content in each formulation was calculated using a standard graph. This procedure was repeated for every formulation and the assay was calculated.

\section{In vitro disintegration}

Each film that contains $10 \mathrm{ml}$ of Phosphate buffer with $\mathrm{pH} 6.8$ is placed in a petri dish. The time taken by each film when it starts to disintegrate was recorded. Average and standard deviations from 3 fast dissolving buccal films were measured and recorded.

\section{In vivo disintegration}

Fast dissolving buccal film is carried out in healthy volunteers (ageing 25-40 years, $n=6$ ) in vivo disintegration time. Before performing the test, the volunteers were aware of the steps and aim of the test. They were told that before placing the piece of fast dissolving buccal film on their tongue, they need to rinse their mouth. They were asked to monitor for the time required by the film to disintegrate and wash off thoroughly. In vivo disintegration times of the selected optimized batches were only carried out due to safety reasons.

\section{In vitro dissolution}

A suitable house method was used for in vivo drug release studies of fast dissolving buccal film, for dissolution to be carried out in USP type-I (basket apparatus) of pH 6.8 medium with $500 \mathrm{ml}$ of Phosphate buffer. The medium was maintained with a temperature of $37 \pm 0.5^{\circ} \mathrm{C}$ stirred at $100 \mathrm{rpm}$. The samples were withdrawn at an interval of $2,5,10,15,20$ min and $30 \mathrm{~min}$ time. At each time interval, $10 \mathrm{ml}$ of the sample was collected and is replaced with the same amount of medium. The samples were analysed in UV/Visible spectrophotometer, bracketing standard after every six samples were measured which was prepared by dissolving the same amount of drug in $500 \mathrm{ml}$ Phosphate buffer $\mathrm{pH} 6.8$ medium.

Solid-state form of drug by X-Ray Diffractometer (XRD): The form of input drug and the drug in the formulation was studied with the help of an X-ray diffractometer. The drug in the formulation must not recrystallize; if the drug in the formulation recrystallizes it gives a nonelegant appeal to the film.

Surface morphology of the formulation by Scanning Electron Microscopy (SEM): The surface morphology of the optimized formulation was studied with the help of Scanning Electron Microscopy (LEO 400).

Stability studies: Stability studies of the formulation were carried out under accelerated stability conditions $(40 \pm 2,75 \pm 5 \%$ R.H.) and normal condition $\left(25 \pm 2^{\circ} \mathrm{C}, 75 \pm 5 \%\right.$ R.H.) for four weeks. The stability samples were withdrawn at two weeks and four weeks duration and were tested for physical appearance, assay and in vitro disintegration time are shown in Table 5. The samples were loaded in LDPE (open condition) and sealed aluminium packs (closed condition).

\section{RESULTS}

\section{Selection of Polymer, Diluent and Disintegrant}

Polymer, diluent and disintegrant Selection are shown in Table 1. PEG 400 , Citric acid, Sodium saccharin shows $60 \%$ that's for the best polymer. HPMC E3:E15 (85:15) shows 50\% that's for the best diluent and best disintegrant.

\section{Result of Polymer, Plasticizer, Diluent Selection Trials}

Polymer has tested for different properties like Film-forming property, Appearance, Peelability, in vitro disintegration time and results are in Table 2. Plasticizers has tested for different properties like Folding endurance, Tensile strength $(\mathrm{N})$, Percentage elongation, in vitro Disintegration time (sec) and results are in Table 2. Diluent has tested for different properties like recrystallization, texture, in vitro disintegration time (sec) and results are in Table 2.

\section{Disintegration time, tensile strength, Percent elongation response as a response}

The Analysis of Variance (ANOVA) result for Disintegration time, tensile strength, Percent elongation response presented in Table 3.

\section{In vitro disintegration}

The in vitro disintegration time of film was increases as the amount of Citric acid and Sodium saccharin increases and increase in concentration of plasticizer decreased disintegration time but after excessive amount of polymer increase, the film became brittle so there was slight decrease in disintegration time. Results of different batches are shown in Table 4.

\section{In vivo disintegration}

The in vitro disintegration time of different batches was found to be between 31-124 sec. Results of different batches are shown in Table 4. 
Table 1: Initial trials for polymer, diluents and disintegrant selection.

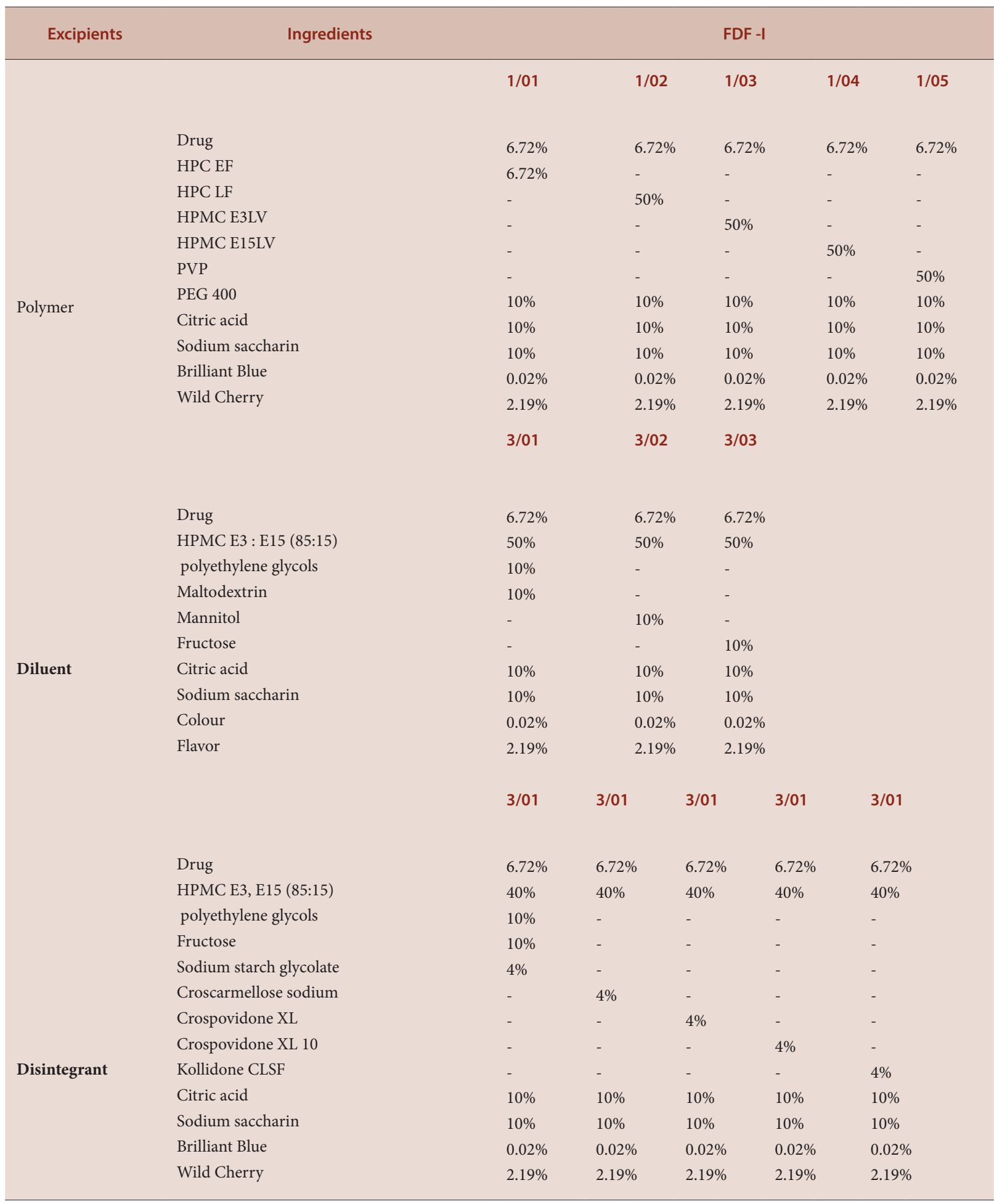

The polymers selected for the initial trial are HPC EF, HPC LF, HPMC E3LV, HPMC E15LV, PVP, PEG 400, Citric acid, Sodium saccharin, Brilliant Blue, Wild Cherry.

The diluents selected for the initial trial are HPMC E3: E15 (85:15), polyethylene glycols, Maltodextrin, Mannitol, Fructose, Citric acid, Sodium saccharin, Colour, Flavour.

The suitable disintegrates for the initial trial are HPMC E3, E15 (85:15), polyethylene glycols, Fructose, Sodium starch glycolate, Croscarmellose sodium Crospovidone XL, Crospovidone XL 10, Kollidone CLSF, Citric acid, Sodium saccharin, Brilliant Blue, Wild Cherry. 


\section{In vitro dissolution}

In vitro drug release study of batches was performed in USP Dissolution Apparatus-I at $37 \pm 0.5^{\circ} \mathrm{C}$ and $100 \mathrm{rpm}$ using $500 \mathrm{ml}$ of $\mathrm{PBS} \mathrm{pH} 6.8$ buffer for $30 \mathrm{~min}$. Cumulative \% drug release of different batches at the end of 5 min was found to be between 85.9 to $97.6 \%$. Results of different batches are shown in Table 5 .

\section{Solid-state form of drug by X-Ray Diffractometer (XRD)}

The X-Ray Diffractometer (XRD) results also confirm the interactions and formation of a single homogenous phase by the appearance of the amorphous halo characteristic of single co-amorphous dispersions.

\section{Scanning Electron Microscopy (SEM)}

SEM images of frovatriptan succinate monoydrate fast dissolving buccal film are presented in Figure 1. SEM of frovatriptan succinate monoydrate fast dissolving buccal film exposes discrete, elongated flake-like structures with rough edges covered on their surfaces by fine particles. Some structures are large with parallelogram shape. It also reveals the hard and thick nature of the drug particles. In contrast, frovatriptan succinate monoydrate complex observed by SEM is soft and thin.

\section{Stability studies}

Accelerated stability studies optimized after 4 weeks and it showed good stable condition. Results of stability studies of different batches are shown in Table 6.

\section{DISCUSSION}

The physicochemical characteristics of the drug were investigated and had a similarity with the internal specifications. The working $\lambda_{\max }$ was determined by using a UV spectrophotometer and was found to be $244 \mathrm{~nm}$, which complied with the internal specifications $\left(\lambda_{\max } 245 \mathrm{~nm}\right) .^{12}$ The taste masking of the films was done by optimizing the concentration of Sodium saccharin (sweetener), citric acid (saliva stimulant and flavour) and fructose (natural sweetener and diluents). The tastes of the optimized films were panel tested by a group of 5 healthy volunteers. The selected formulations after the panel testing were evaluated statistically to see if there was any significant difference in the three formulations. ${ }^{13}$ The evaluation was done applying one way ANOVA using the KruskalWallis test. Post-test, the formulations were compared to each other using Dennett's multiple comparison tests. Prism 5.0 software was used for calculation and analysing the results. The concentration of Sodium saccharin, citric acid and fructose from the most desirable batch was selected and kept constant in further formulation optimization, to mask the taste of the drug effectively.

For the optimization procedure, a three-level simplex lattice mixture design was used. Three factors, concentration of Polymer (HPMC) (A), Plasticizer (polyethylene glycols) (B) and Disintegrant (C), were used in the design and the responses were in vitro disintegration time (Y1), Tensile strength (Y2) and Percentage elongation (Y3). ${ }^{14}$

Based on a Simplex lattice mixture design, a total of 14 batches were prepared by solvent casting method and evaluated based on in vitro disintegration time, Tensile strength and Percentage elongation. The in vitro disintegration time of different batches was found to be between $32-122 \mathrm{sec}$. The tensile strength of various batches was found to be in the

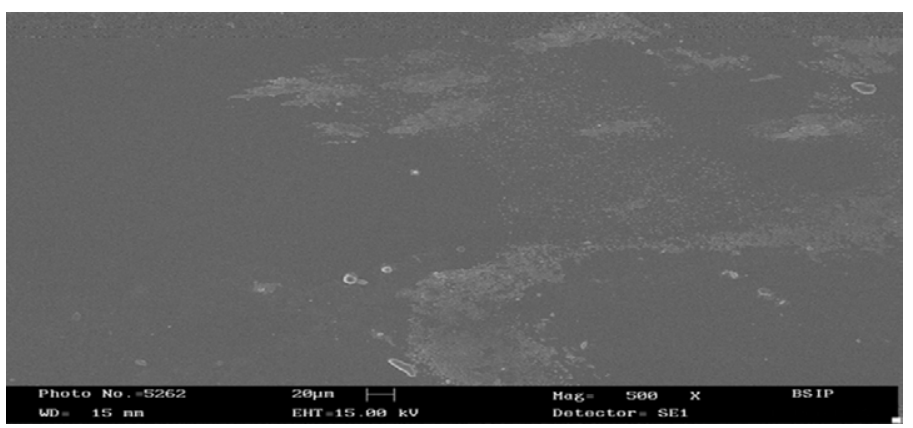

Figure 1: Scanning Electron Microscope (SEM) Image of fast dissolving buccal film at $400 x$ magnification.

Table 2: Result of Polymer, Plasticizer, Diluent Selection Trials.

\begin{tabular}{|c|c|c|c|c|}
\hline \multirow[t]{2}{*}{ Excipients } & \multirow[t]{2}{*}{ Property tested } & \multicolumn{3}{|c|}{ FDF -I } \\
\hline & & $1 / 06$ & $1 / 07$ & $1 / 08$ \\
\hline \multirow{5}{*}{ Polymer } & Film-forming property & & & \\
\hline & Appearance & 2 & 2 & 2 \\
\hline & Peelability & 1 & 1 & 1 \\
\hline & In vitro disintegration time & 2 & 1 & 2 \\
\hline & & 172 & 169 & 166 \\
\hline \multirow{5}{*}{ Plasticizer } & & $1 / 08$ & $1 / 09$ & $1 / 10$ \\
\hline & Folding endurance & 127 & 231 & 153 \\
\hline & Tensile strength $(\mathrm{N})$ & 5.95 & 11.57 & 8.81 \\
\hline & Percentage elongation & $2.3 \%$ & $8.7 \%$ & $3.7 \%$ \\
\hline & In vitro Disintegration time (sec) & 165 & 168 & 172 \\
\hline \multirow{5}{*}{ Diluent } & & $3 / 02$ & $3 / 02$ & $3 / 03$ \\
\hline & Recrystallization & & & \\
\hline & Texture & No & Yes & No \\
\hline & In vitro disintegration time (sec) & Rough & - & Smooth \\
\hline & & 158 & - & 138 \\
\hline
\end{tabular}

The in vitro disintegration time and texture of FDF -I-3/03 was found to be acceptable.

The different formulations like FDF -II-1/6, FDF -II-1/7, FDF -II-1/8 were selected for panel testing and found to be overall accepted 
Table 3: ANOVA for Mixture Special Cubic Model for Disintegration Time Response, Tensile Strength Response and Percentage Elongation Response.

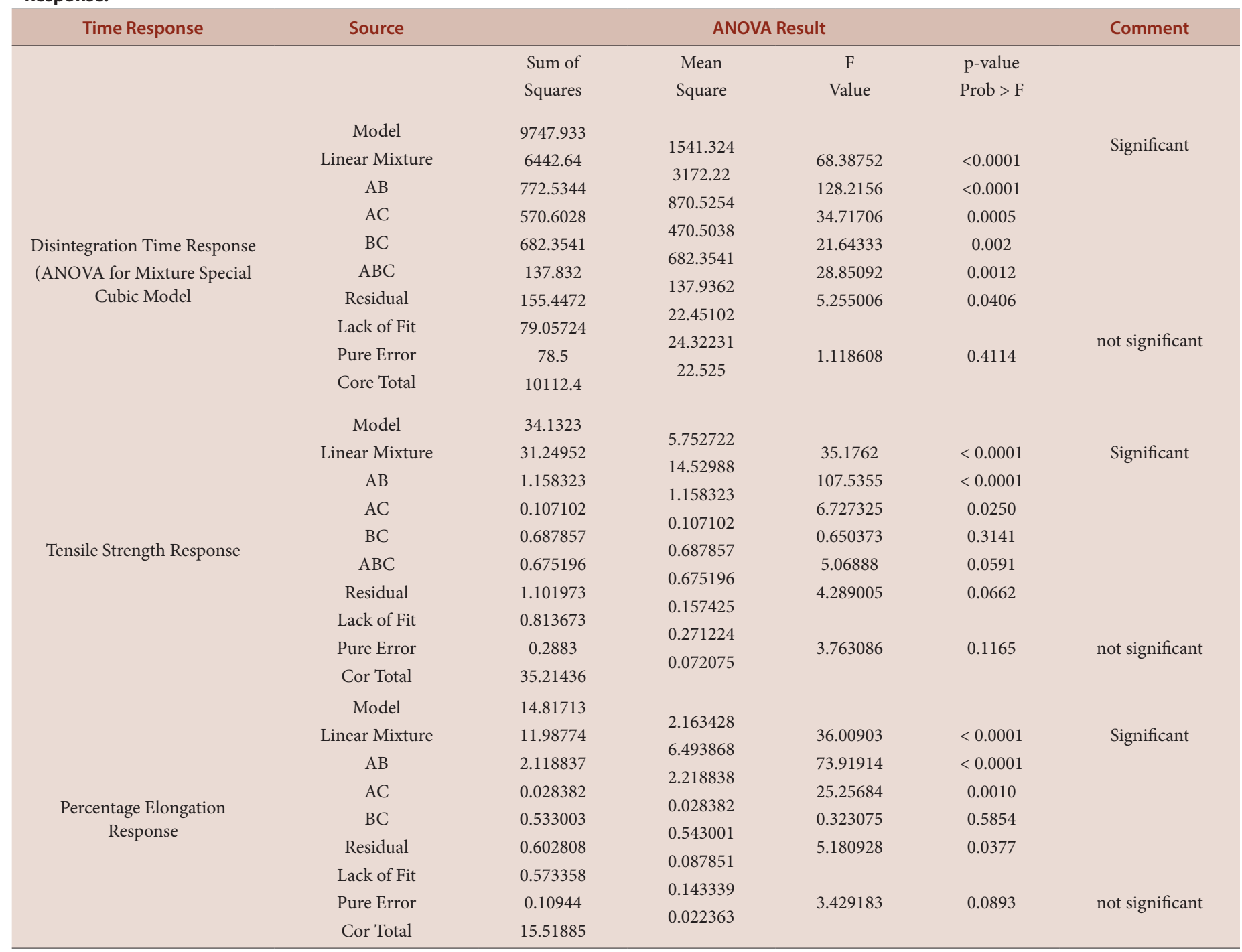

Different model values were presented as mean \pm S.D. $(n=3)$.

range of 4.35 to $9.20 \mathrm{MPa}$. The Percentage elongations of various batches were found to be in the range of 2.48 to $5.88 \%$. In vitro drug release study of batches was performed in USP Dissolution Apparatus-I at $37 \pm 0.5^{\circ} \mathrm{C}$ and $100 \mathrm{rpm}$ using $500 \mathrm{ml}$ of PBS pH 6.8 buffer for $30 \mathrm{~min}$. Cumulative $\%$ drug release of different batches at the end of $5 \mathrm{~min}$ was found to be between 84.9 to $98.4 \% .^{15}$

The Optimized batch (OB) fast dissolving film (FDF)-III-1/7 was determined by using the software Design Expert. The optimized batch (OB) was prepared with concentrations of Polymer, Plasticizer and disintegrate at $43.33,8.33$ and 3.33 respectively by solvent casting method. Optimized batch (OB) showed in vitro disintegration time of $42 \mathrm{sec}$, Tensile strength of $7.36 \mathrm{MPa}$ and Percentage elongation of $4.43 \%$. The results of Scanning Electron Microscope (SEM) (Figure 1) showed that uniformity in size and shape of frovatriptan succinate monohydrate fast dissolving buccal film. The Scanning Electron Microscope (SEM) of fast dissolving buccal film at 500X demonstrated the characteristic amorphous aggregates and presence of the defined shape of crystals. The fast dissolving buccal film prepared from solvent casting method showed an almost clear, transparent glassy and homogenous film with wholly dissolved into the polymer matrix. ${ }^{16}$
Table 4: Result of in vitro/ in vivo Disintegration DOE Batches.

\begin{tabular}{|c|c|c|c|}
\hline Evaluation parameter & Method/time & Formulation & D.T. (sec) \\
\hline \multirow{17}{*}{ Disintegration } & \multirow{14}{*}{ In vitro } & FDF -III-1/1 & $30.5 \pm 0.5$ \\
\hline & & FDF -III-1/2 & $46 \pm 1$ \\
\hline & & FDF -III-1/3 & $52 \pm 1$ \\
\hline & & FDF -III-1/4 & $66.5 \pm 2$ \\
\hline & & FDF -III-1/5 & $34.5 \pm 1.4$ \\
\hline & & FDF -III-1/6 & $32.5 \pm 0.5$ \\
\hline & & FDF -III-1/7 & $41 \pm 1$ \\
\hline & & FDF -III-1/8 & $65.5 \pm 1.4$ \\
\hline & & FDF -III-1/9 & $51.5 \pm 0.5$ \\
\hline & & FDF -III-1/10 & $66.5 \pm 0.5$ \\
\hline & & FDF -III-1/11 & $123.5 \pm 1.4$ \\
\hline & & FDF -III-1/12 & $46.5 \pm 1.5$ \\
\hline & & FDF -III-1/13 & $110.5 \pm 0.5$ \\
\hline & & FDF -III-1/14 & $56.5 \pm 0.5$ \\
\hline & \multirow{3}{*}{ In vivo } & FDF -II-1/6 & 16.16 \\
\hline & & FDF -II-1/7 & 17.66 \\
\hline & & FDF -II-1/8 & 15.33 \\
\hline
\end{tabular}

In vitro/ in vivo disintegration time of different batches FDF III and FDF II 
Table 6: Result of Accelerated Stability Studies.

\begin{tabular}{|c|c|c|c|c|c|}
\hline $\begin{array}{l}\text { Storage } \\
\text { condition }\end{array}$ & Duration & Type & $\begin{array}{l}\text { Colour } \\
\text { change }\end{array}$ & Assay & $\begin{array}{c}\text { In vitro } \\
\text { disintegration } \\
\text { time }(\mathrm{sec})\end{array}$ \\
\hline $\begin{array}{c}40 \pm 2^{\circ} \mathrm{C} \\
75 \pm 5 \% \text { R.H. }\end{array}$ & $\begin{array}{l}\text { Two } \\
\text { weeks }\end{array}$ & Open & Yes & $94.42 \pm 0.66$ & $34 \pm 0.34$ \\
\hline $\begin{array}{c}40 \pm 2^{\circ} \mathrm{C} \\
75 \pm 5 \% \text { R.H. }\end{array}$ & $\begin{array}{l}\text { Two } \\
\text { weeks }\end{array}$ & Closed & No & $97.86 \pm 2.65$ & $32 \pm 0.5$ \\
\hline $\begin{array}{c}40 \pm 2^{\circ} \mathrm{C} \\
75 \pm 5 \% \text { R.H. }\end{array}$ & $\begin{array}{l}\text { Four } \\
\text { weeks }\end{array}$ & Open & Yes & $93.78 \pm 0.93$ & $36 \pm 0.72$ \\
\hline $\begin{array}{c}40 \pm 2^{\circ} \mathrm{C} \\
75 \pm 5 \% \text { R.H. }\end{array}$ & $\begin{array}{l}\text { Four } \\
\text { weeks }\end{array}$ & Closed & No & $96.61 \pm 1.92$ & $34 \pm 1.4$ \\
\hline
\end{tabular}

Stability data of different formulations were presented as mean \pm S.D. $(n=3)$.

The X-Ray Diffractometer (XRD) spectrum of Optimized Batch Placebo Formulation of fravotriptan Succinate monohydrate results also confirm the interactions and formation of a single homogenous phase by the appearance of the amorphous halo characteristic of single coamorphous dispersions. ${ }^{16}$ The incorporation of fast dissolving buccal film ascorbic acid co-amorphous dispersions in fast dissolving buccal film was intended to provide a simple, easily administered dosage form for the application inside the mouth. The formulated film was found to have an acceptable transparent appearance and mechanical properties, disintegration and dissolution. ${ }^{17}$ Almost complete dissolution from the film was attained within $10 \mathrm{~min}$. Also, the drug was found to be stable in the film for up to 12 weeks at $40^{\circ} \mathrm{C}$ and $75 \% \mathrm{RH}$ which could be attributed to compatibility between polymers used in the film. This increased phase stability possibly occurred through extending the super saturation state. The optimized fast dissolving buccal film formula obtained by the model was chosen for testing the physicochemical stability. Stability study of the optimized batch was carried out at accelerated condition and was found to be stable with no colour change when packed and sealed in aluminium foil, for four weeks. ${ }^{17}$

\section{CONCLUSION}

From the present study, it may be concluded that the fast dissolving films of frovatriptan succinate monohydrate can be prepared by the solvent casting method using HPMC E3 and E15 in 85:15 ratio respectively by using polyethylene glycols as plasticizer, croscarmellose sodium as a disintegrant and fructose as a natural sweetener and diluents. The final formula was optimized by simplex lattice mixture design using StatEase design expert software to give the optimized batch. The optimized batch (OB) prepared with concentrations of Polymer, Plasticizer and disintegrant at $42.32,7.32$ and 4.32 respectively by solvent casting method. Optimized batch $(\mathrm{OB})$ showed in vitro disintegration time of $44 \mathrm{sec}$, Tensile strength of $6.35 \mathrm{MPa}$ and Percentage elongation of $3.62 \%$.

\section{ACKNOWLEDGEMENT}

Special thanks to, higher authorities of Glocal University, Saharanpur to help and provide moral support for this research work.

\section{CONFLICT OF INTEREST}

The authors declare that there is no conflict of interest.

\section{ABBREVIATIONS}

FTIR: Fourier Transform Infrared Spectroscopy; FDF: fast dissolving films; DOE: Design of experiment; SEM: Scanning Electron Microscope; 
HPMC: Hydroxypropyl methylcellulose; HPC: Hydroxypropyl cellulose; PVP: Polyvinylpyrrolidone.

\section{REFERENCES}

1. Silberstein SD, Stiles MA, Young WB. Atlas of Migraine and Other Headaches. $2^{\text {nd }}$ ed. London: Taylor and Francis group. 2005.

2. Burch R, Rizzoli P, Loder E. The prevalence and impact of migraine and severe headache in the United States: Figures and trends from government health studies. Headache. 2018;58(4):496-505.

3. Macgregor AE. Menstrual migraine: A clinical review. J Fam Plann Reprod Health Care. 2007;33(1):36-47.

4. Saylor D, Steiner TJ. The global burden of headache: Scanning electron microscope (sem) in Neurol. Thieme Medical Publishers. 2018;38(2):182-90.

5. Siddiqui M, Garg G, Sharma P. A Short Review on a Novel Approach in Oral Fast Dissolving Drug Delivery System and Their Patents. Adv Biol Res. 2010;5(6):291303.

6. Chaudhari VA, Sarode SM, Sathe BS, Vadnere GP. Mucoadhesive buccal drug delivery system: A review. Int J Pharm Sci. 2014;5(2):142-59.

7. Shimoda H, Taniguchi K. Preparation of fast dissolving oral thin film containing dexamethasone: A possible application to antiemesis during cancer chemotherapy. Eur J Pharm Biopharm. 2009;73(3):361-5.

8. Comer MB. Pharmacology of the selective $5-\mathrm{HT}_{1 \mathrm{~B} / 1 \mathrm{D}}$ agonist frovatriptan. Headache. 2002;42(2):47-53.

9. Brown AM, Ho M, Thomas DR, et al. Functional effects of frovatriptan (VML 251), sumatriptan and naratriptan on human recombinant $5-\mathrm{HT}_{1}$ and $5-\mathrm{HT}_{7}$ receptors Headache. 1998;38:376.

10. Buchan P. The pharmacokinetics of frovatriptan (VML 251/SB 209509), a potent selective 5-HT1B/1D agonist, following single dose administration by oral and intravenous routes to healthy male and female volunteers. Func Neurol. 1998;13:177.

11. Buchan $P$, Keywood C, Wade A, et al. Clinical pharmacokinetics of frovatriptan Headache. 2002;42(2):54-62.

12. Abualhasan M, Mansour J, Jaradat N, Zaid A, Khadra I. Formulation and Development of a Validated UV-Spectrophotometric Analytical Method of Rutin Tablet. Int Sch Res Notices. 2017;1-7. doi: 10.1155/2017/2624947

13. Chattopadhyay S, Raychaudhuri $U$, andChakraborty R. Artificial sweeteners: A review. J Food Sci Technol. 2014;51(4):611-21.

14. Chaudhary $\mathrm{H}$, et al. Development and optimization of fast dissolving orodispersible films of granisetron $\mathrm{HCl}$ using Box-Behnken statistical design. Bull Fac Pharm Cairo Univ. 2013;51(2):193-201.

15. Gohel M, et al. Application of Simplex Lattice Design and Desirability Function for the Formulation Development of Mouth Dissolving Film of Salbutamol Sulphate. Curr Drug Deliv. 2009;6(5):486-94.

16. Löbmann K, et al. Amino Acids as Co-Amorphous Stabilizers for Poorly Wate Soluble Drugs-Part 1: Preparation, Stability and Dissolution Enhancement. Eur J Pharm Biopharm. 2013;85(3):873-81.

17. Kawakami K. Modification of Physicochemical Characteristics of Active Pharmaceutical Ingredients and Application of Supersaturatable Dosage Forms for Improving Bioavailability of Poorly Absorbed Drugs. Adv Drug Deliv Rev. 2012;64(6):480-95.

Article History: Submission Date : 29-08-2020; Revised Date : 12-11-2020; Acceptance Date : 28-01-2021

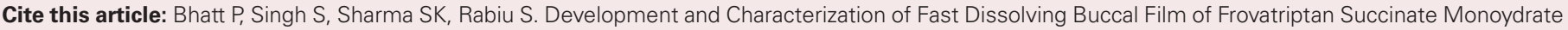
for Buccal Delivery. Int. J. Pharm. Investigation. 2021;11(1):69-75 